\title{
Perencanaan dan Pengawasan Pembangunan Gedung Kelas di Sekolah Dasar Islamic Global School (IGS) Kota Malang untuk Meningkatkan Mutu Pendidikan
}

\section{(Planning and Supervision of Class Building Construction in Islamic Global School (IGS) Malang City to Improve Education Quality)}

\author{
Taufikkurrahman $^{1 *}$, Arif Wahono ${ }^{2}$, Lila Kurnia Wardani ${ }^{3}$ \\ 1,2,3 Program Studi Teknik Sipil, Fakultas Teknik, Universitas Wisnuwardhana - Malang
}

\begin{abstract}
ARTICLE INFO
ABSTRAK

Article history

Received : 08 April 2021

Revised : 01 Juni 2021

Accepted : 08 Juni 2021

DOI :

https://doi.org/10.33366/jast.v5i1 .2310

Keywords : classroom;

construction; planning;

supervision

*e-mail corresponding author : taufikkurrahman73@gmail.com

Sekolah Dasar Islamic Global School (SD-IGS) Malang adalah salah satu sekolah swasta yang berada di kota Malang. Berdiri pada tahun 2010 pada lahan seluas $10.000 \mathrm{~m} 2$. Seiring dengan pertambahan jumlah siswa yang terus meningkat seiring dengan tercapainya peringkat akreditasi B, maka kebutuhan akan sarana prasarana kelas sangat penting. Kondisi kelas yang ada, masih terdapat bangunan kelas yang sudah tua dengan kondisi bangunan yang mengkhawatirkan keamanannya. Tujuan dari pengabdian ini adalah untuk menyediakan dokumen gambar kerja dan rencana anggaran biaya pembangunan ruang kelas sebagai dasar untuk pelaksanaan pembangunan. Metode yang digunakan adalah metode difusi iptek. Pengabdian masyarakat ini menghasilkan sebuah produk dokumen perencanaan ruang kelas dan diperoleh kesimpulan sebagai berikut: (1) telah tersedianya dokumen perencanaan pembangunan ruang kelas; (2) telah terlaksananya pembangunan tahap 1 ruang kelas yang memiliki dokumen pelaksanaan pembangunan yang sesuai standar peraturan yang berlaku.
\end{abstract}

\section{PENERBIT}

\section{UNITRI PRESS}

Jl. Telagawarna, Tlogomas-

Malang, 65144, Telp/Fax:

0341-565500

\section{(c) (†) (?)}

This is an open access article under the Creative Commons Attribution-ShareAlike $\quad \mathbf{4 . 0}$ International License. Any further distribution of this work must maintain attribution to the author(s) and the title of the work, journal citation and DOI. CC-BY-SA

\section{ABSTRACT}

Elementary School of Islamic Global School (SD-IGS) Malang is one of the private schools located in Malang and established in 2010 in 10,000 m2. With the increasing number of students continues to grow in line with the achievement of accreditation rank $B$, the need for classroom infrastructure is very important. The condition of the existing class, there are still old class buildings with the condition of the building is worrying on safety. This devotion aims to provide detailed engineering design documents and budget plans for the cost of building classrooms as the basis for classroom construction. The method used is the science diffusion method. This community service produces a product of classroom planning documents and obtains the following conclusions; (1) there has been a plan of development activities in the form of classroom development planning documents; (2) the implementation of the construction of phase 1 classrooms that have development implementation documents that comply with the applicable regulatory standards.

Cara Mengutip : Taufikkurrahman, T., Wahono, A., Wardani, L. K. (2021). Perencanaan dan Pengawasan Pembangunan Gedung Kelas di Sekolah Dasar Islamic Global School (IGS) Kota Malang untuk Meningkatkan Mutu Pendidikan. JAST : Jurnal Aplikasi Sains dan Teknologi, 5(1), 32-43. doi:https://doi.org/10.33366/jast.v5i1.2310 


\section{PENDAHULUAN}

Salah satu indikator terwujudnya kualitas pendidikan yang baik adalah tersedianya sarana dan prasarana yang memadai. Ketersediaannya tersebut juga harus memenuhi persyaratan dan standar minimal yang ditetapkan dalam peraturan bangunan. Ruang kelas adalah fasilitas pendidikan yang digunakan untuk kegiatan pembelajaran. Di dalam ruang kelas terjadi proses pembelajaran dan interaksi antara guru dengan murid [1]. Proses pembelajaran akan berhasil dan berjalan dengan baik jika murid dan guru merasakan keamanan dan kenyamanan di dalam ruang kelas. Keamanan dan kenyaman dalam ruang kelas ini pada gilirannya akan menunjang dan mendukung peningkatan mutu pendidikan. Beberapa penelitian menunjukkan adanya hubungan antara kualitas ruang kelas dengan prestasi siswa [2,3].

Sekolah Dasar Islamic Global School (SD-IGS) Malang yang beralamat di Jl. S. Supriadi No.35, Bandungrejosari, Kec. Sukun, Malang, adalah salah satu sekolah swasta yang berada di kota Malang. Berdiri pada tahun 2010 pada lahan seluas $10.000 \mathrm{~m} 2$. Sekolah yang berada di bawah naungan Yayasan Dian Nusantara ini merupakan perwujudan dari pihak Yayasan untuk turut mencerdaskan dan mempersiapkan anak bangsa yang berkarakter Islami dan berkualitas, khususnya di Kota Malang. SD IGS Sudah memiliki status akreditasi dengan nilai B. Dengan status tersebut, terjadi peningkatan calon siswa yang mendaftar ke sekolah tersebut setiap tahunnya. Pada tahun pelajaran 2020/2021, terdapat 24 rombongan belajar yaitu sejumlah 619 siswa. Jumlah ini meningkat dari tahun sebelumnya, yaitu sebanyak 493 siswa (23 rombongan belajar).

Dengan keadaan tersebut berakibat tidak mencukupinya sarana ruang kelas serta prasarana lainnya karena jumlah siswa yang terus bertambah. Selain itu kondisi bangunan sekolah/ruang kelas banyak yang sudah tidak memadai dari segi fisiknya. Secara struktur, bangunan/ruang kelas sudah tidak memadai untuk proses pembelajaran, karena sudah berumur/tua. Kondisi struktur atap yang sudah lapuk dan terjadi kebocoran jika hujan. Pihak sekolah mengkhawatirkan kondisi bangunan tersebut dari segi keamanan struktur bangunannya. Apalagi akhir-akhir ini kota Malang sering mengalami gempa. Hal ini dapat dimaklumi karena sekolah ini menggunakan bangunan lama yang diakuisisi pihak Yayasan dari sekolah sebelumnya. Solusi yang dapat dilakukan adalah dengan cara melakukan renovasi ruang kelas tersebut dengan menjadikan bangunan yang lebih kuat dan permanen dengan cara membongkar rangka atap yang sudah lapuk lalu menggantinya menjadi dak/plat beton serta menjadikan bangunan tersebut menjadi bangunan dua lantai untuk menambah ruang kelas.

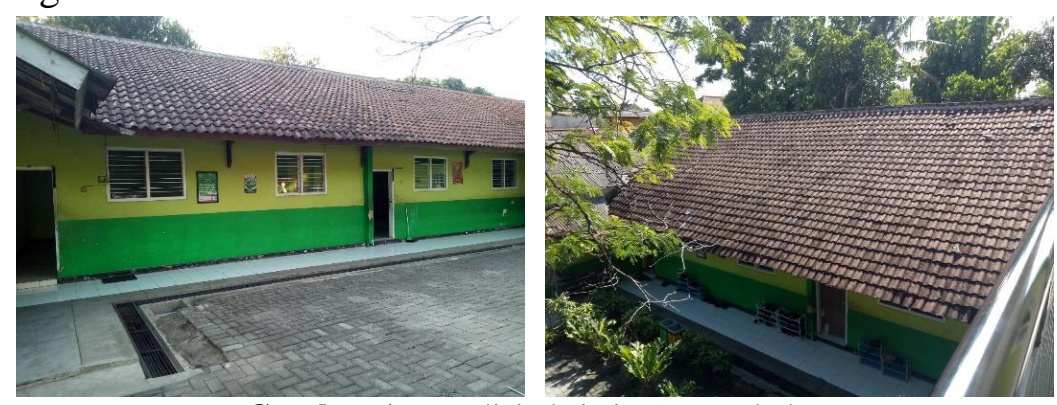

Gambar 1. Kondisi eksisting ruang kelas 
Sebagai tindak lanjut dari rencana tersebut, pihak sekolah meminta bantuan berupa pendampingan perencanaan bangunan ruang kelas dan pengawasan pelaksanaan pembangunan ruang kelas SD IGS Malang kepada tim dari program studi Teknik sipil Universitas Wisnuwardhana Malang.

Tujuan akhir kegiatan pengabdian kepada masyarakat ini diharapkan dapat diperoleh struktur bangunan sekolah/ruang kelas yang yang memenuhi persyaratan bangunan gedung, sehingga dapat menjamin keamanan dan kenyamanan dalam proses pembelajaran.

\section{METODE KEGIATAN}

Kegiatan pengabdian ini berupa jasa konsultansi perencanaan bangunan ruang kelas dan pengawasan pembangunan ruang kelas SD IGS Malang.

Pelaksanaan kegiatan yang dilakukan meliputi proses perancangan berupa denah, tampak dan gambar detail serta pengawasan selama proses pembangunan. Proses perancangan berlangsung selama kurang lebih satu bulan sedangkan pelaksanaan pembangunan berlangsung kurang lebih empat bulan. Tahapan kegiatan terdiri dari beberapa kegiatan, yaitu: (1) tahap konsep, (2) observasi dan (3) perancangan.

\section{Konsep}

Tahap awal kegiatan konsultasi adalah tahap konsep berupa wawancara dan diskusi dua arah dengan pihak sekolah mengenai ide, rencana, persepsi dan ekspektasi peruntukan bangunan ruang kelas yang diinginkan. Dari hasil konsultasi pada tahap ini dapat diketahui bahwa pihak sekolah berencana untuk membuat bangunan kelas dua lantai di lokasi bangunan lama dengan masih memanfaatkan tembok/dinding lantai 1 gedung ruang kelas yang lama.

\section{Observasi Lapangan}

Tinjauan ke lapangan dilakukan untuk pendataan dan pengukuran kondisi kelas eksisting, melihat kondisi bangunan. Dari hasil kegiatan ini didapat dokumentasi berupa foto dan data pengukuran yang dijadikan dasar proses analisis pra desain.

\section{Perancangan}

Secara arsitektur langkah analisis pertama adalah analisis ruang mencakup identifiasi aktivitas yang akan diakomodir, kebutuhan ruang, standar ruang dan program ruang. Kemudian langkah berikunya adalah melakukan penyusunan kebutuhan ruang serta penyusunan tata ruang untuk menentukan sirkulasi berbagai ruang yang telah didesain sehingga sesuai dengan keinginan dan kebutuhan rencana [4]. Hasil desain layout ruangan dapat dilihat pada gambar 4. Struktur bangunan ruang kelas ini direncanakan dengan menggunakan material beton bertulang. Berdasarkan SNI Beton [5], bangunan ruang kelas direncanakan dengan sistem struktur dasar penahan lateral dengan Sistem Rangka Pemikul Momen Khusus (SRPMK). 
Metode yang dilakukan pada kegiatan pengabdian masyarakat ini adalah Difusi Iptek. Difusi iptek adalah teori yang membicarakan tentang bagaimana sebuah ide dan teknologi baru tersebar dalam sebuah kebudayaan [6]. Difusi Iptek adalah kegiatan pengabdian masyarakat yang menghasilkan produk bagi konsumen baik internal maupun eksternal. Pengabdian masyarakat ini menghasilkan sebuah produk desain ruang kelas untuk SD IGS Malang.

\section{KARYA UTAMA}

Program pengabdian yang dilaksanakan ini akan menghasilkan produk berupa dokumen perencanaan yang terdiri dari gambar rencana bangunan ruang kelas, perhitungan struktur dan perhitungan anggaran biaya untuk kegiatan pelaksanaan. Dokumen rencana disediakan lebih awal dimaksudkan agar pada saat pembangunan sudah tidak ada kendala secara teknis. Dokumen desain ini juga bertujuan sebagai lampiran yang melengkapi proposal permohonan bantuan dana ke instansi terkait dan atau sponsor. Hasil kegiatan pengabdian ini diuraikan sebagai berikut.

\section{Observasi Lapangan}

Pada saat observasi lapangan dilakukan pengukuran bangunan eksisting dan pendataan kondisi bangunan, jaringan listrik, air minum dan lain lain. Survey dilakukan bersama dengan pihak sekolah, sehingga diketahui kebutuhan dan rencana pengembangan yang diinginkan melalui pengamatan, wawancara dan diskusi.
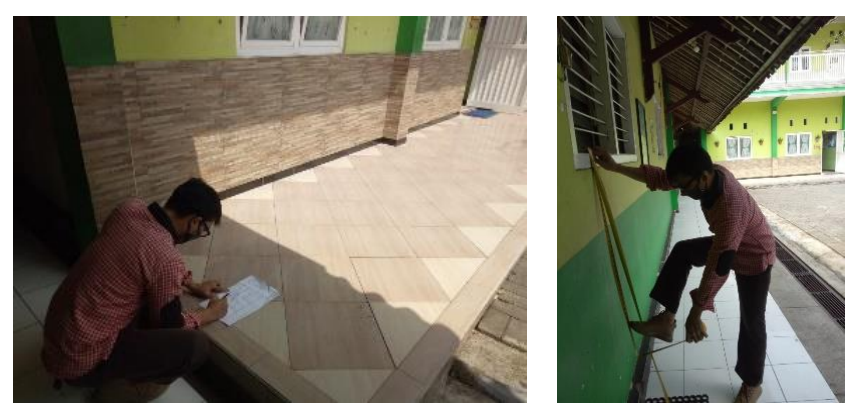

Gambar 2. Proses observasi dan pengukuran

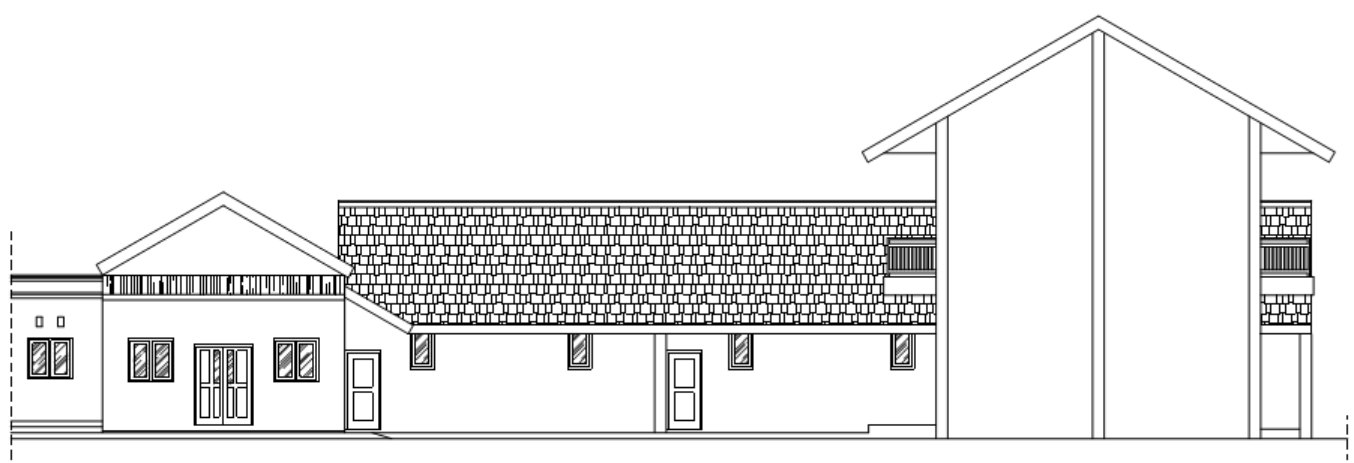

Gambar 3. Tampak Depan ruang kelas Eksisting 


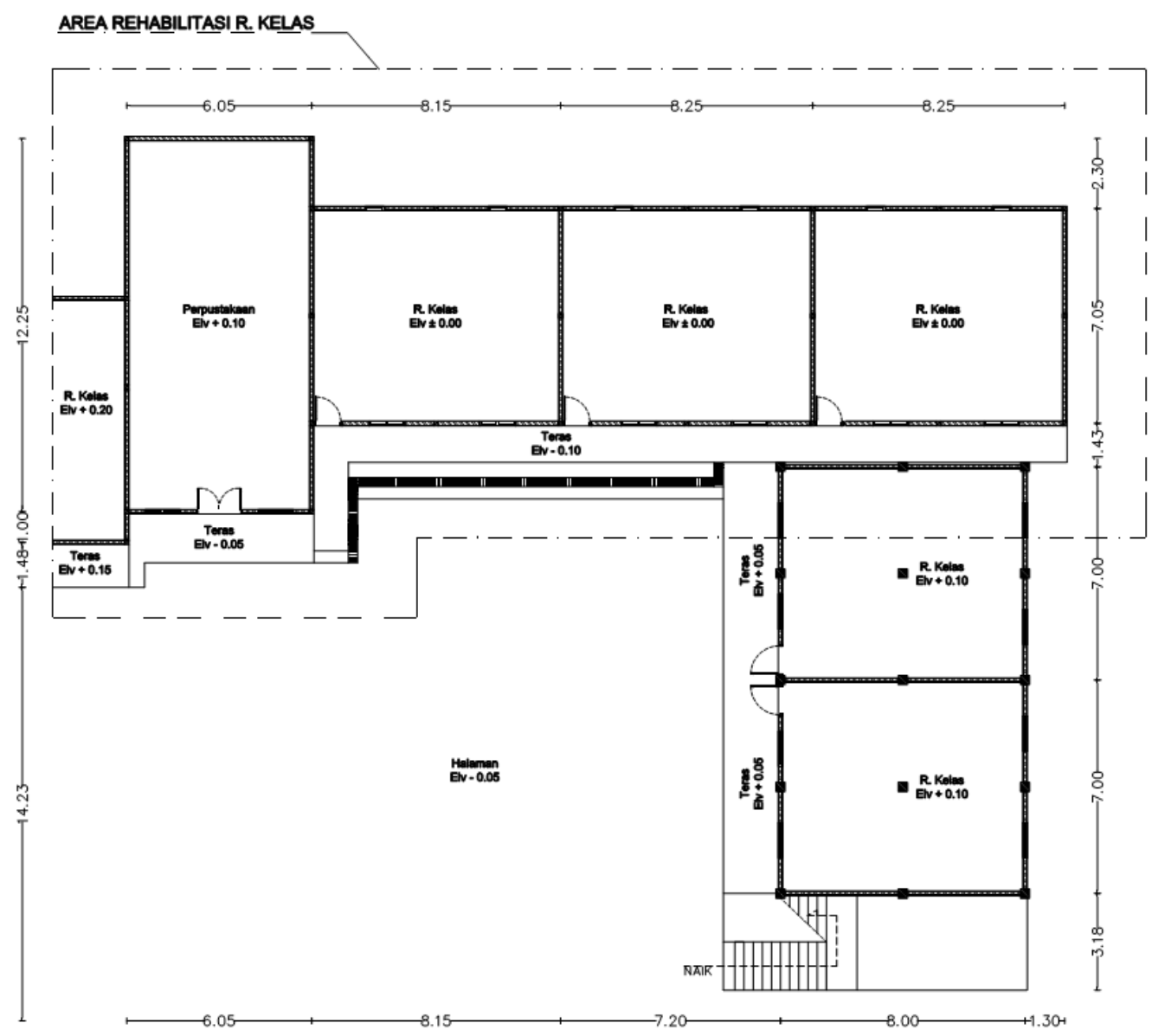

Gambar 4. Denah ruang kelas eksisting

\section{Perancangan}

Langkah pertama dari perancangan adalah membuat gambar pradesain berdasarkan hasil observasi lapangan. Pembuatan gambar pradesain dilakukan berdasarkan hasil survey lapangan. Gambar pra desain ini terdiri dari: (a) denah, dan tampak. Beberapa gambar pra desain dapat dilihat pada gambar 5 berikut.

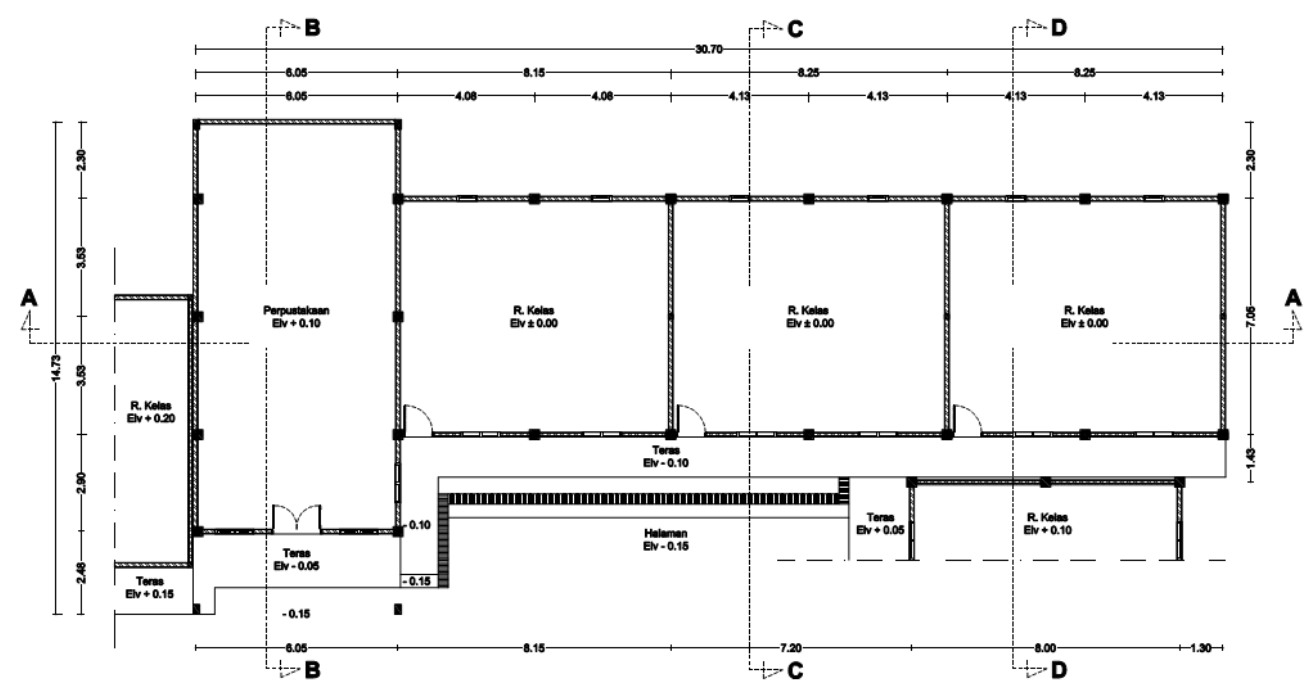




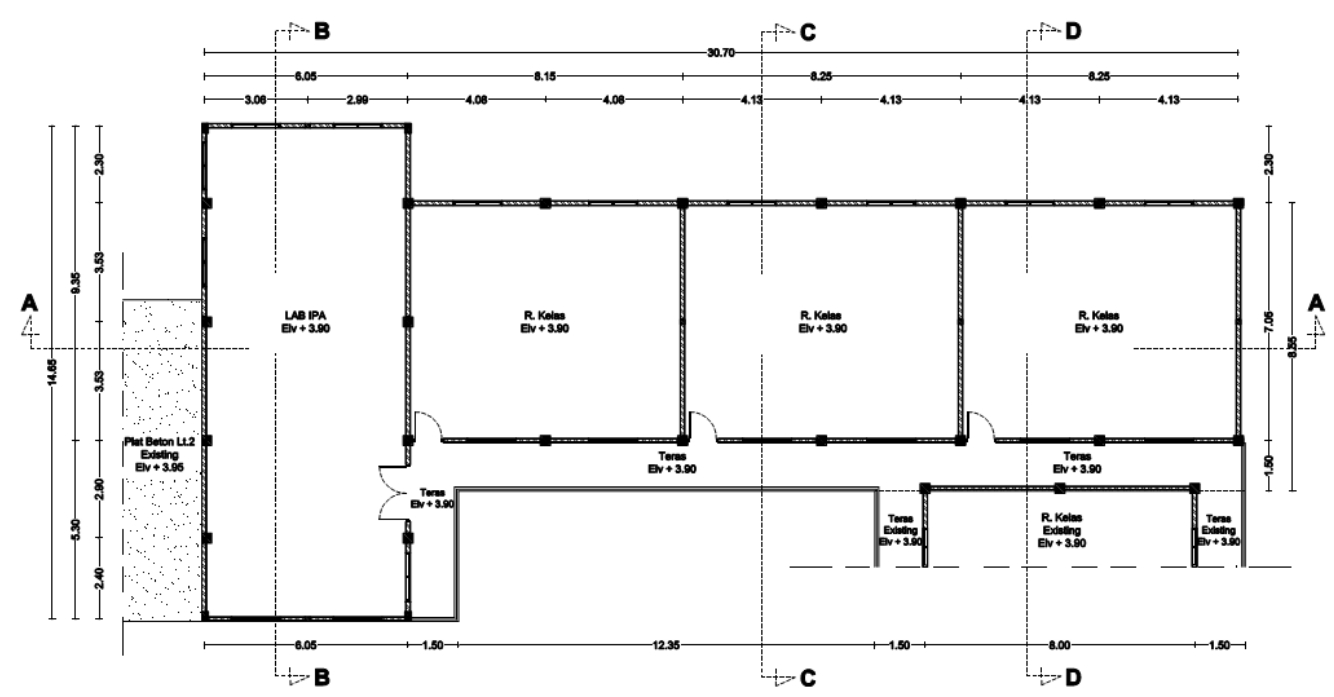

Gambar 5. Rencana Denah lantai 1 dan 2

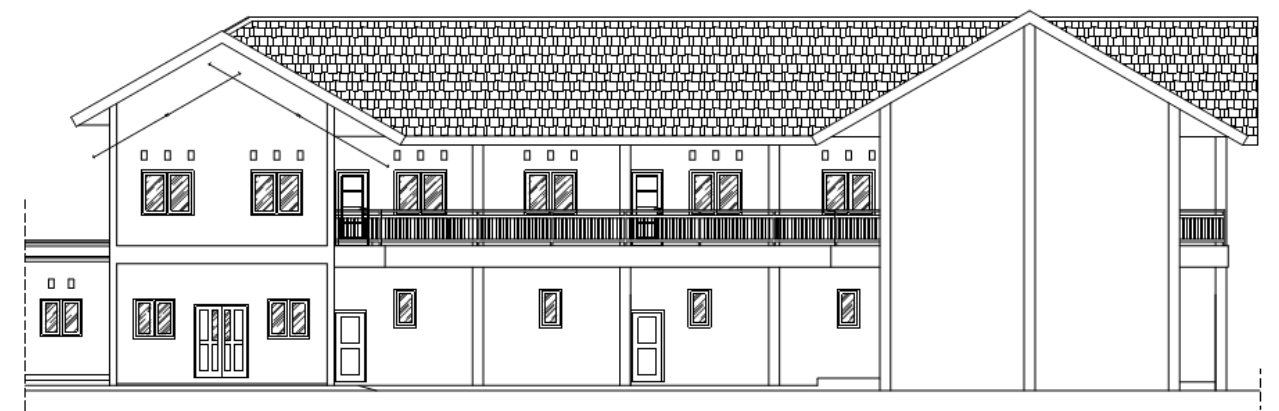

Gambar 6. Tampak Depan ruang kelas

Perhitungan struktur merupakan tahapan selanjutnya yang harus dibuat untuk dapat memberikan jaminan keandalan dan keamanan bangunan.

Perhitungan struktur dimaksudkan agar struktur yang direncanakan stabil, kuat dan efisien dan memiliki kemudahan dalam pelaksanaan [7]. Suatu struktur bangunan dinyatakan stabil jika struktur tersebut tidak terguling, mengalami kemiringan dan ataupun tidak mengalami pergeseran selama umur bangunan yang telah direncanakan. Agar tujuan perencanaan tersebut tercapai, maka perhitungan struktur direncanakan dengan mengikuti peraturan yang berlaku.

Struktur bangunan ruang kelas didesain dengan menggunakan material beton bertulang. Bangunan ruang kelas direncanakan dengan sistem struktur dasar penahan lateral dengan Sistem Rangka Pemikul Momen Khusus (SRPMK) [8]. Perhitungan beban yang bekerja meliputi beban mati, beban hidup dan beban gempa [9]. Untuk pemodelan struktur digunakan program ETABS v.2016.Penggunaan software ETABS sudah sangat jamak dalam membantu untuk menghitung gaya-gaya dalam pada struktur bangunan [10],[11]. Dari hasil pemodelan dan perhitungan struktur menggunakan program ETABS. Hasil perhitungan struktur Gedung ruang kelas SD IGS Malang adalah sebagai berikut: 
a. Pondasi yang digunakan menggunakan pondasi telapak dengan ukuran $1,0 \mathrm{x} 1,0 \mathrm{~m}, \mathrm{t}=0,3$ $\mathrm{m}$ dengan kedalaman pondasi adalah $1,5 \mathrm{~m}$.

b. Untuk kolom diperoleh dimensi 30x30 dengan tulangan 8D13 dan sengkang Ø10-150.

c. tebal untuk pelat lantai beton $12 \mathrm{~cm}$ di elv.+ 4.00 menggunakan tulangan Ø10-200.

d. Balok B1 dimensi 30x60 dengan tulangan atas 7D16, tulangan tengah 2Ø10, tulangan bawah 3D16 dan sengkang Ø 8-150

e. Balok B2 dimensi 25x40 dengan tulangan atas 2D16, tulangan tengah 2Ø10, tulangan bawah 2D16 dan sengkang Ø8-200

f. Ring Balok dimensi $15 \times 20$ dengan tulangan atas $2 \varnothing 12$, tulangan bawah $2 \varnothing 12$ dan sengkang Ø8-200.

g. Untuk konstruksi atap menggunakan konstruksi atap baja ringan dengan penutup atap genteng karangpilang

Selanjutnya adalah penyusunan gambar detail adalah tahapan lanjutan yang mendasarkan pada gambar pradesain dan perhitungan struktur yang telah dibuat. Gambar detail ini mencakup gambar-gambar detail yang terdiri dari:

1. Gambar Rencana Denah

2. Gambar Struktur

3. Rencana lantai keramik

4. Rencana plafon

5. Rencana listrik dan titik lampu

6. Rencana kusen dan pintu

Selanjutnya setelah gambar rencana sudah selesai menginjak tahapan berikutnya yaitu menyusun Rencana anggaran biaya $(\mathrm{RAB})$. Item pekerjaan yang terdapat pada RAB meliputi pekerjaan-pekerjaan sebagai berikut :

\section{Lantai 1}

I Pekerjaan Pendahuluan

1 Pekerjaan Mobilisasi

2 Bongkaran atap

3 Bongkaran plafon

4 Bongkaran lantai

II Pekerjaan Tanah

1 Penggalian tanah biasa sedalam $1 \mathrm{~m}$

2 Pengurugan kembali galian tanah

3 Pembuangan tanah sejauh 30 meter

4 Pengurugan $1 \mathrm{M} 3$ dengan pasir urug

III Pekerjaan Beton

1 Lantai kerja Beton

2 Pondasi Tapak

3 Kolom

4 Balok

5 Plat Lantai 
IV Pekerjaan Dinding

1 Dinding Bata Merah Campuran 1SP : 4PP

2 Plesteran 1SP : 4PP Tebal $15 \mathrm{~mm}$

3 Acian

4 Benangan

5 Dinding keramik ukuran $20 \times 25 \mathrm{~cm}$

VI Pekerjaan Penutup Lantai

1 lantai keramik ukuran 60 × $60 \mathrm{~cm}$

VII Pekerjaan Pengecatan

1 Pengecatan tembok baru interior

2 Pengecatan tembok baru eksterior

3 Pengecatan plafon

4 Pengecatan Bidang Kayu Baru

\section{Pekerjaan Listrik}

1 Pemasangan titik lampu XL 23 Watt

2 Pemasangan titik lampu XL 18 Watt

3 Pemasangan stop kontak

5 Pemasangan saklar ganda

X Pekerjaan Plafon

1 List langit-langit gypsum

\section{Lantai 2}

I Pekerjaan Tanah

1 Pasir urug bawah lantai

II Pekerjaan Beton

1 Kolom

a Beton Mutu, f'c = 19,3 MPa (K225)

b Pembesian dengan Besi Polos

c Pasang bekisting untuk kolom

2 Membuat $1 \mathrm{~m}$ ' Ring Balok Beton Bertulang $(10 \times 15) \mathrm{cm}$

III Pekerjaan Dinding

1 Pemasangan 1m2 Dinding Bata Merah Campuran 1SP : 6PP

2 Pemasangan $1 \mathrm{~m} 2$ Plesteran 1SP : 4PP Tebal $20 \mathrm{~mm}$

3 Pemasangan $1 \mathrm{~m} 2$ Plesteran 1SP : 6PP Tebal $20 \mathrm{~mm}$

4 Pemasangan $1 \mathrm{~m} 2$ Acian

5 Benangan

6 Pasang dinding keramik ukuran 20 x $25 \mathrm{~cm}$

IV Pekerjaan Almunium dan Kaca

1 Pemasangan $1 \mathrm{~m}$ Kusen Pintu Alumunium

2 Pembuatan dan pemasangan daun pintu panel, kayu kelas III

3 Pemasangan $1 \mathrm{~m} 2$ Kaca Tebal $5 \mathrm{~mm}$

V Pekerjaan Penutup Lantai

1 Pasang lantai keramik ukuran $30 \times 30 \mathrm{~cm}$ putih

VI Pekerjaan Pengecatan

1 Pengecatan tembok baru interior

2 Pengecatan tembok baru eksterior

3 Pengecatan plafon 


\section{Pekerjaan Listrik}

1 Pemasangan titik lampu XL 23 Watt

2 Pemasangan titik lampu XL 18 Watt

2 Pemasangan stop kontak

3 Pemasangan saklar tunggal

4 Pemasangan saklar ganda

\section{Pekerjaan Pengunci}

1 Pemasangan Kunci Silinder

2 Pemasangan Kunci Slot

3 Pemasangan Engsel Pintu

4 Pemasangan Engsel Jendela Kupu-kupu

5 Pasang grendel jendela

6 Pasang hak angin

\section{Pekerjaan Besi}

1 Pasang pagar besi hollow

\section{Pekerjaan Penutup Atap}

1 Pasang Atap Baja Ringan untuk Penutup Atap Genteng

2 Pasang atap genteng karangpilang ex. Malang

3 Pasang bubung genteng karangpilang ex. Malang

4 Pasang talang tegak pipa PVC f 4"

5 Pasang lisplang ukuran (30) $\mathrm{cm}$, woodplank

6 Pasang talang datar, seng bjls $30 \mathrm{~L}=0.60 \mathrm{~m}$

\section{$X$ Pekerjaan Plafon}

1 Pasang Rangka Plafon Metal Furing

2 Pemasangan $1 \mathrm{~m} 2$ Langit-langit Asbes Semen, Tebal $4 \mathrm{~mm}, 5 \mathrm{~mm}$, dan $6 \mathrm{~mm}$

3 List langit-langit gypsum

Adapun Rencana anggaran Biaya tersebut adalah sebagai berikut :

Tabel 1. Rekapitulasi Rencana Anggaran Biaya

\begin{tabular}{|c|c|c|}
\hline No. & Jenis Pekerjaan & Jumlah \\
\hline 1 & LANTAI 1 & \\
\hline I & Pekerjaan Pendahuluan & $16,879,499$ \\
\hline II & Pekerjaan Tanah & $4,443,840$ \\
\hline III & Pekerjaan Beton & $314,473,109$ \\
\hline IV & Pekerjaan Dinding & $38,423,886$ \\
\hline VI & Pekerjaan Penutup Lantai & $69,066,144$ \\
\hline VII & Pekerjaan Pengecatan & $30,392,733$ \\
\hline VIII & Pekerjaan Listrik & $20,397,291$ \\
\hline \multirow[t]{2}{*}{$\mathrm{X}$} & Pekerjaan Plafon & $5,783,928$ \\
\hline & Jumlah LANTAI 1 & $499,860,434$ \\
\hline 2 & LANTAI 2 & \\
\hline I & Pekerjaan Tanah & $2,124,997$ \\
\hline II & Pekerjaan Beton & $49,864,288$ \\
\hline III & Pekerjaan Dinding & $138,914,372$ \\
\hline IV & Pekerjaan Almunium dan Kaca & $25,121,483$ \\
\hline $\mathrm{V}$ & Pekerjaan Penutup Lantai & $53,185,956$ \\
\hline VI & Pekerjaan Pengecatan & $46,205,327$ \\
\hline VII & Pekerjaan Listrik & $17,903,481$ \\
\hline VIII & Pekerjaan Pengunci & $7,462,121$ \\
\hline IX & Pekerjaan Besi & $31,640,479$ \\
\hline IX & Pekerjaan Penutup Atap & $230,850,288$ \\
\hline \multirow[t]{3}{*}{$\mathrm{X}$} & Pekerjaan Plafon & $49,288,607$ \\
\hline & Jumlah LANTAI 2 & $652,561,405$ \\
\hline & Jumlah Harga Konstruksi & $1,152,421,839$ \\
\hline
\end{tabular}




\section{Pengawasan Pelaksanaan}

Pada saat pelaksanaan pembangunan ruang kelas, maka kegiatan pengabdian ini berupa pendampingan untuk pengawasan pembangunan ruang kelas. Tujuan dari pendampingan ini adalah agar saat pelaksanaan pembangunan ruang kelas, benar-benar dilaksanakan sesuai dengan dokumen rencana yang sudah di buat.

Tim pengawas melakukan pengawasan dengan cara melakukan inpeksi pada hari Rabu dan Sabtu setiap minggunya. Namun jika terjadi hal-hal yang mendesak maka tim akan datang jika diperlukan atau bisa melakukan konsultasi melalui media telpon dan atau media WhatsApp. Beberapa Dokumentasi saat pelaksanaan disajikan pada gambar 7 berikut.

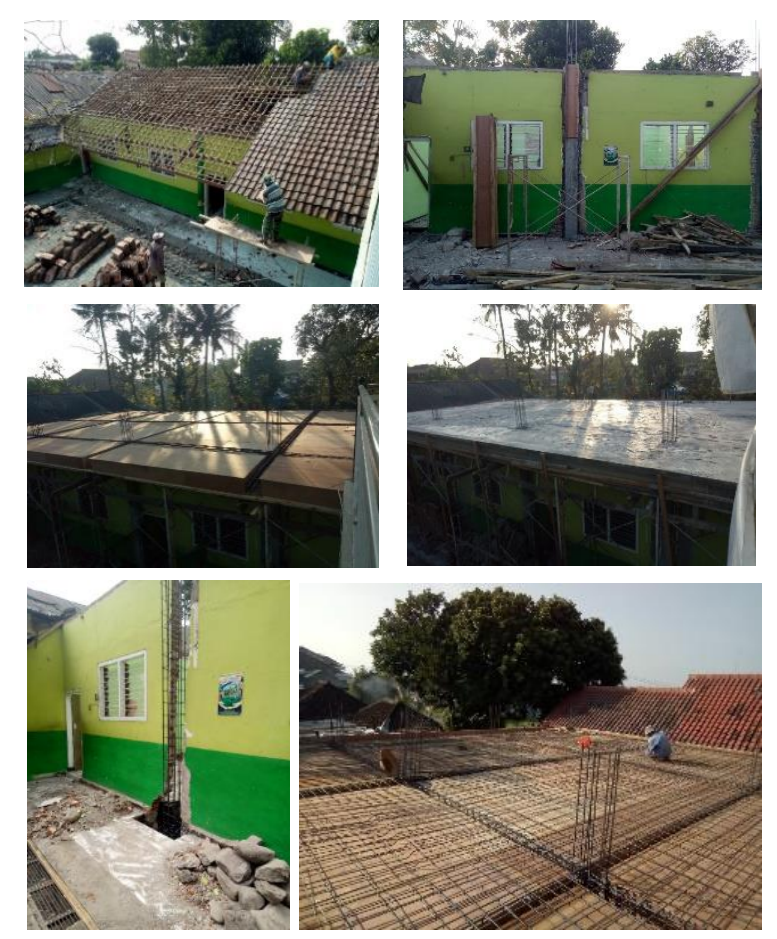

Gambar 7. Pelaksanaan pembangunan ruang kelas

\section{ULASAN KARYA}

Pelaksanaan pengabdian yang dilakukan oleh tim pengabdian di SD Islamic Global Scholl (IGS) kota Malang merupakan salah bentuk penerapan bidang ilmu teknik sipil dalam rangka menyelesaikan permasalahan yang ada pada mitra (SD IGS kota Malang). Dengan adanya kegiatan pengabdian ini maka tersedia dokumen perencanaan gedung kelas yang sesuai standar perencanaan yang berlaku. Dokumen perencanaan ini digunakan untuk melakukan pelaksanaan pembangunan.

\section{DAMPAK DAN MANFAAT KEGIATAN}

Manfaat dari pelaksanaan pengadian ini adalah tersedianya dokumen perencanaan Gedung ruang kelas yang sesuai dengan standar bangunan Gedung sekolah. Dokumen ini digunakan sebagai dasar untuk melaksanakan pembangunan. Selain itu dengan 
terlaksananya kegiatan ini maka tersedia fasilitas Pendidikan berupa ruang kelas yang dalam proses pelaksanaan pembangunannnya dilakukan pengawasan terhadap seluruh aspek baik dari segi waktu, kualitas material serta metode pelaksanaan. Terbangunnya ruang kelas dengan kualitas baik ini akan meningkatkan kenyamanan dan keamanan.

\section{KESIMPULAN}

Sebagai penutup dari kegiatan Pengabdian Kepada Masyarakat ini, maka disampaikan hal-hal sebagai berikut:

1. Telah tersedianya rencana kegiatan pembangunan berupa dokumen perencanaan pembangunan ruang kelas yang terdiri dari gambar arsitektur dan struktur. Gambar arsitektur berupa denah pembagian ruang dan tampak, sedangkan gambar struktur berupa denah pondasi, denah pembalokan dan denah kolom.

2. Telah terlaksananya pembangunan tahap 1 ruang kelas yang memiliki dokumen pelaksanaan pembangunan yang sesuai standar peraturan yang berlaku.

Keberlanjutan kerjasama dengan mitra merupakan wujud kepercayaan mitra kepada kompetensi yang dilakukan oleh para pengabdi, yaitu Tim dari Universitas Wisnuwardhana Malang.

Sampai dengan saat ini, pembangunan ruang kelas masih sampai kepada tahap 1 yaitu sampai pada pengecoran dak lantai 2 dan sudah selesai. Sehingga pelaksanaan pengabdian pada pembangunan tahap 1 ini sudah selesai dilaksanakan.

Sedangkan pembangunan tahap ke 2 yaitu pekerjaan ruang kelas lantai 2 akan dikerjakan pada tahap berikutnya yang direncanakan akan dilaksanakan pada akhir tahun 2021. Pada saat tahap kedua ini dilaksanakan maka pendampingan dari tim pengabdi akan dilanjutkan untuk melakukan pengawasan pada pembangunan ruang kelas tahap tersebut yaitu pekerjaan finishing ruang kelas dan juga pengembangan infrastruktur lainnya di kawasan sekolah SD IGS Malang ini.

\section{PENGHARGAAN}

Penulis mengucapkan terima kasih yang sebesar-besarnya kepada pihak sekolah SD IGS Malang yang telah memberikan kesempatan kepada kami untuk melakukan pengabdian kepada masyarakat ini.

\section{DAFTAR PUSTAKA}

[1] G. Sukowiyono et al., "PERENCANAAN GEDUNG KELAS SEBAGAI TAMPAK DEPAN," vol. IV, pp. 31-38.

[2] M. J. Mendell and G. A. Heath, "Erratum: Do indoor pollutants and thermal conditions in schools influence student performance? A critical review of the literature (Indoor Air 15:1 (27-52))," Indoor Air. 2005.

[3] D. Mumovic, L. Chatzidiakou, and R. Ahmed, "Designing schools for health, comfort and cognitive performance: What do we know?," in Designing Buildings 
for the Future of Schooling: Contemporary Visions for Education, 2018.

[4] B. A. Wibawa and R. S. Saraswati, "Perencanaan Pembangunan Masjid Al-Ikhwan Kelurahan Karangayu, Semarang," E-Dimas, vol. 7, no. 1, p. 1, 2016.

[5] SNI 2847 : 2013, "Persyaratan Beton Struktural untuk Bangunan Gedung," Bandung Badan Stand. Indones., 2013.

[6] S. Mulyana, "Peranan komunikasi dalam difusi teknologi," no. 1981, 2008.

[7] D. Prasetyo, N. S. Pujaningtyas, and A. Kristiawan, "Perencanaan Struktur Gedung Lab School Universitas Pgri Semarang," J. Ilm. Teknosains, vol. 5, no. 1, p. 57, 2019.

[8] Sni 1726:2012, “Tata Cara Perencanaan Ketahanan Gempa Untuk Struktur Bangunan Gedung dan Non Gedung (SNI 1726:2012)," Sni 17262012, 2012.

[9] Badan Standardisasi Nasional, "SNI 1727-2013," Beban Minim. untuk Peranc. Bangunan Gedung dan Strukt. Lain, 2013.

[10] R. J. Honarto, B. D. Handono, and R. Pandaleke, "PERENCANAAN BANGUNAN BETON BERTULANG DENGAN SISTEM RANGKA PEMIKUL MOMEN KHUSUS DI KOTA MANADO,” J. Sipil Statik, 2019.

[11] R. Alfianto and D. Rahmat, "Analisa Perhitungan Bangunan Dengan Metode Etabs Versi 9.7.2,” J. Civ. Eng. Build. Transp., 2019. 